Our patient had no features of phenytoin toxicity despite a concentration of $31.3 \mathrm{mg} / \mathrm{l}$. After starting tolbutamide the phenytoin concentration decreased to $27.4 \mathrm{mg} / \mathrm{l}$. The total concentration was measured, not the free level. Neither the Committee on Safety of Medicines nor the manufacturer knows of any othe cases of phenytoin toxicity produced by tolbutamide.

1 Wesseling $\mathbf{H}$, Mols-Thurkow I. Interaction of diphenylhydantoin (DPH) and tolbutamide in man. Eur $\mathcal{J}$ Clin Pharmacol 1975;8:75

2 Pannekoek JH, cited by Wesseling et al.

\section{Convulsion and coma after intranasal desmopressin in cystic fibrosis}

Drs E J Simmonds, M J Mahony, and J M Littlewoon (Regional Cystic Fibrosis Unit, St James's Hospital, Leeds LS9 7TF) write: Desmopressin has been advocated as a treatment for nocturnal enuresis. ${ }^{2}$ We report on a child with cystic fibrosis who developed water intoxication while being treated with desmopressin. The patient, a girl aged 13 years, had made good progress apart from recurrent nasal polyps requiring operative removal. By the age of 12 however, she had developed chronic Pseudomonas aeruginosa respiratory infection and began three monthly admissions for intravenous antibiotics During one of these she started taking intravenou azlocillin ( $5 \mathrm{~g}$ three times a day) and tobramycin $(130 \mathrm{mg}$ three times a day). Pancreatic and vitamin supplements were continued. She also had primary nocturnal enuresis resistant to normal therapeutic interventions so we decided to try desmopressin nasal spray. She was given four doses on consecutive nights: $10 \mu \mathrm{g}, 20 \mu \mathrm{g}, 20 \mu \mathrm{g}, 10 \mu \mathrm{g}$.

On the morning after her fourth dose of desmopressin the patient developed headache, nausea, and vomiting. She had remained dry for the first time the previous night. Review of her weight chart showed a sharp weight gain since treatment started: $41 \cdot 35 \mathrm{~kg}$ to $43 \cdot 15 \mathrm{~kg}$. On the third day of treatment serum sodium concentration had been $125 \mathrm{mmol} / \mathrm{l}$ and on the fourth day this had fallen to $114 \mathrm{mmol} / \mathrm{l}$. Later that day she had a convulsion lasting about five minutes and subsequently remained comatose. Her desmopressin was discontinued and she was managed with fluid restriction alone to prevent possible pontine myelinolysis.+ Twenty eight hours after her last dose of desmopressin she passed urine again and continued to pass good quantities of dilute urine. Forty hours after fluid restriction was started intravenous fluids with her normal daily sodium requirements were started. Her serum sodium concentration rose and five days later was normal $(135 \mathrm{mmol} / \mathrm{l})$.

Forty eight hours after her convulsion she was still deeply comatose, however. Physical examination showed response only to deep pain, poor corneal reflexes, absent cough reflex, and absent peripheral reflexes. Computed tomography of her head and lumbar puncture showed nothing abnormal. She gradually regained consciousness and over two weeks returned to normal with no neurological sequelae.

This patient with cystic fibrosis had a severe adverse response to intranasal desmopressin used in doses recommended by the manufacturer; several authors have reported that desmopressin by this route is safe for both short ${ }^{12}$ and long term' treatment of nocturnal enuresis. There are no reports of water intoxication, although mild side effects were noted in a few patients treated with intranasal desmopressin for diabetes insipidus. ${ }^{\circ}$ It is not clear why our patient responded as she did. The duration of action of nasally administered desmopressin is variable, ${ }^{7}$ depending on its rate of clearance from the nose. Our patient's nasal mucosa had the abnormal physical and electrical properties associated with cystic fibrosis as well as nasal polyps, so the duration of action of the drug may have been prolonged by any of these factors. In the light of what is known about the basic defect in cystic fibrosis it is tempting to speculate that this patient's sensitivity to desmopressin, resulting in abnormality of sodium and water homoeostasis, is linked to the chloride channel block described. ${ }^{\gamma}$ We would recommend that desmopressin should be used with great caution in children with cystic fibrosis or nasal polyps. At the very least careful weighing and frequent electrolyte measurements should be done.

1 Aladjen M, Wohl R, Boichis H, Ordo S, Lotan D, Freedman S Desmop
Dimsou SB. DDAVP and urine os
Arch Dis Child 1986;61:1104-7.

zaff $M$, Hoiby N, Fleusberg EW. Frequent antibiotic therapy improves survival of cystic fibrosis patients with chronic $651-7$.

4 Lasureno R, Karp BI. Pontine and extrapontine myelinolysis following rapid correction of hyponatraemia. Lancet 1988; : 1439-40.

5 Rew DA, Rundle JSH. An assessment of the safety of regular DDAVP therapy in primary nocturnal enuresis. Br $\mathcal{F}$ Urol (in press)

6 Marek J, Loutocky A, Pacovsky V, Zasoral M. Ten year experience with DDAVP in treatment of diabetes insipidus. Endokrnologie 1978;72:188-94.

Seif SM, Zenser TV, Garochi FF, Davis BB, Robinson AG. DDAVP (1-desamino-8-D-arginine-vasopressin) treatment of central diabetes insipidus: mechanism of prolonged antidiuresis. F Clin Endocrinol Metab 1978;46:381-8.

8 Quinton PM. Chloride impermeability in cystic fibrosis. Nature 1983;301:421-2.

\section{Severe hypersensitivity reaction to fenbufen}

Dr M M Muthiah (Bassetlaw District General Hospital, Worksop S81 0BD) writes: The common side effects of the non-steroidal anti-inflammatory drug fenbufen are mild gastrointestinal disturbance, rash, and neurological symptoms. ${ }^{2}$ The potentially serious side effects are peptic ulceration and gastrointestinal haemorrhage. I report here a serious systemic reaction.

A 41 year old previously healthy woman was given fenbufen $900 \mathrm{mg} /$ day for a painful left knee. She took it for 10 days, and four days after stopping the drug she developed a generalised erythematous rash and became unwell with throat pain, fever, and rigors. There was no history of arthritis, drug allergy, asthma, or eczema. On examination she was ill (temperature $40^{\circ} \mathrm{C}$ ) with generalised lymphadenopathy and an extensive erythematous exfoliative rash affecting the whole body and face. The left knee was swollen and tender. Investigations showed: haemoglobin $133 \mathrm{~g} / \mathrm{l}$, white cell count $42 \times 10^{9} / \mathrm{l}$, eosinophils $10 \cdot 1 \times 10^{4} / 1$, neutrophils $14.7 \times 10^{4} / 1$, platelets $139 \times 10^{\%} / \mathrm{l}$, prothrombin time $2.4 \mathrm{~s}$, activated partial thromboplastin time $41 \mathrm{~s}$ (control 21-32), fibrinogen normal. Aspartate aminotransferase activity was $1015 \mathrm{IU} / 1$ (normal 0-40), lactate dehydrogenase $2190 \mathrm{IU} / \mathrm{l}(230-460)$, alkaline phosphatase 1233 IU/l (100-280), and albumin $30 \mathrm{~g} / \mathrm{l}$. A PaulBunnell test, autoantibody screen, and toxoplasma antibody titres were all negative. Erythrocyte sedimentation rate, chest radiograph, radiograph of the left knee, and calcium and phosphate concentrations were normal. Immunoglobulins showed a polyclonal rise. On admission the bone marrow showed a grossly reactive picture with eosinophilia and increased mature lymphocytes.

Four days later she was deeply jaundiced with persistent fever. Repeat blood cultures were negative. Her haemoglobin started to drop and was $5 \mathrm{~g} / 110$ days after admission. Investigations confirmed a Coombs positive autoimmune haemolytic anaemia. Prednisolone $60 \mathrm{mg} / \mathrm{day}$ was started, with considerable improvement in the jaundice and liver function within four days. At this stage a liver biopsy showed swollen liver cells with focal cholestasis. Portal areas contained polymorphs with proliferation of bile ductules. The appearances were those of a resolving hepatitis. Lymph node biopsy showed fatty infiltration with atrophy and no evidence of lymphoma. Liver function values continued to improve after two weeks of steroid therapy, and the haematological and liver function abnormalities completely resolved. She was discharged with advice against using nonsteroidal anti-inflammatory drugs. Follow up over a year confirmed that she was well with normal full blood count and liver function values.

Fenbufen was first marketed in the United Kingdom in 1980 and was the most commonly reported suspect drug on yellow cards in 1986 and $1987 .{ }^{3}$ Eighty per cent of these reports concerned mucocutaneous reactions, including erythema multiforme and Stevens-Johnson syndrome. There have been reports of allergic vasculitis, hepatitis with rash, haemolytic anaemia, and lymphadenopathy. Skin reactions have been reported with other non-steroidal drugs such as ibuprofen

The onset of illness in relation to drug intake, eosinophilia, and other features such as rash, lymphadenopathy, and a hepatic picture raise the strong possibility of drug induced hypersensitivity in this patient. The rapid resolution of clinical and laboratory abnormalities with prednisolone was consistent with this. The differential diagnosis is angioimmunoblastic lymphadenopathy, which is known to occur as a hypersensitive reaction to therapeutic agents.

1 Brock PG, Jackson D. UK general practitioners' experience of fenbufen in elderly patients. Eur $\mathcal{F}$ Rheumatol Inflamm 1982;5:326-31.

2 Becker A, Hoffmeister RT. Fenbufen-a new non steroidal antiinflammatory agent in rheumatoid arthritis, its efficacy and toxicity. F Int Med Res 1980;8:333-38.

3 Committee on Safety of Medicines. Current problems No 23. 1988; Sept.

4 Sonnenblick M, Abraham AS. Ibuprofen hypersensitivity in systemic lupus erythematosus. $B r$ Med $\mathcal{F}$ 1978;i:619.

\section{Azapropazone induced hepatitis}

Drs T C N Lo and I W Dymock (Department of Medicine, Stepping Hill Hospital, Stockport) write: Hepatotoxicity is a rare but increasingly recognised side effect of most non-steroidal anti-inflammatory drugs, ${ }^{1}$ and several cases of fatal hepatitis have been reported. ${ }^{23}$ Nevertheless, complete recovery after early withdrawal of the offending drug usually occurs if the possible link is recognised. ${ }^{+}$We report a case of azapropazone induced hepatitis in which complete recovery followed withdrawal of the drug.

A 57 year old woman was given azapropazone (Rheumox) $600 \mathrm{mg}$ twice daily for osteoarthritis of both hips. Two weeks later she developed generalised erythema multiforme with slight involvement of the mucus membranes of the lips and mouth. She was admitted a week later with slight jaundice. There was no lymphadenopathy, hepatosplenomegaly, or ascites. She had no history of recent travel, contact with jaundiced patients, blood transfusion, injections, or tattoos. She was not taking other medication and did not abuse alcohol. Laboratory investigations showed: haemoglobin $133 \mathrm{~g} / \mathrm{l}$, white cell count $11.3 \times 10^{4} / 1$ with $4 \%$ eosinophils, plasma total bilirubin concentration $42 \mu \mathrm{mol} / \mathrm{l}$, aspartate transaminase $500 \mathrm{IU} / \mathrm{l}, \gamma$ glutamyltransferase $22 \mathrm{IU} / \mathrm{l}$, alkaline phosphatase $311 \mathrm{IU} / \mathrm{l}$, total protein $62 \mathrm{~g} / \mathrm{l}$ (albumin $35 \mathrm{~g} / \mathrm{l}$ ), prothrombin time $17 \mathrm{~s}$ (control 12). She was negative for antinuclear factor, antimitochondrial antibodies, and antismooth muscle antibodies and had had no recent infection with herpes simplex virus, Epstein-Barr virus, cytomegalovirus, varicella zoster, or rubella. Tests for hepatitis A and B were also negative.

Azapropazone was stopped and her jaundice and rash resolved within one week of admission. A percutaneous liver biopsy performed 10 days after admission showed mild centrilobular cholestasis, slight fatty change, and scanty inflammatory cells distributed widely throughout the liver parenchyma. The Kupffer cells were prominent and contained periodic acid Schiff positive, diastase resistant material. Several portal tracts showed moderate to severe chronic inflammatory change similar to that seen in chronic persistent hepatitis with occasional multinucleated giant cells and ill defined granuloma. The overall appearances were those of mild non-specific hepatitis with granuloma formation consistent with drug induced hepatitis. She remained well with normal liver function values one month and three months after discharge.

The manufacturers have received only two reports of "suspected" adverse reactions affecting the liver since azapropazone was marketed in 1976. In each case the link could not be substantiated because of lack of definite temporal relations between drug ingestion and the onset of symptoms and both patients were taking several drugs. The two week interval between the start of treatment and the onset of symptoms in our patient together with negative virological and immunological results suggested a drug induced hypersensitivity reaction, though the underlying mechanism is still unknown.' We have reported this case to the Committee on Safety of Medicines.

We thank Dr N L Reeve for his help in reporting the histological findings in this paper.

1 Ludwig J, Axelsea R. Drug effects on the liver. An updated tabular compilation of drugs and drug-related hepatic disease. Dig Dis Sci 1983;28:651-60.

2 Breen EG, McNicholl J, Cosgrove E, McCabe J, Stevens FM. Fatal hepatitis associated with diclofenac. Gut 1986;27:1390-3. 3 Lee SM, Williams R. Subacute hepatic necrosis induced by piroxicam. Br Med (1984;293:540-1.

4 Dunk AA, Sherlock SS. Diclofenac hepatitis. Br Med $\mathcal{J}$ 1982;284:1065-6.

5 Williams R, Maddray W. Liver gastroenterology 4. London: Butterworth International, 1984:133-64. 